University of Wollongong

Research Online

Faculty of Social Sciences - Papers (Archive) Faculty of Arts, Social Sciences \& Humanities

$1-1-2017$

Continued participation in youth sports: the role of achievement motivation

Lauren Gardner

University of Wollongong, lag994@uowmail.edu.au

Stewart A. Vella

University of Wollongong, stvella@uow.edu.au

Christopher A. Magee

University of Wollongong, cmagee@uow.edu.au

Follow this and additional works at: https://ro.uow.edu.au/sspapers

Part of the Education Commons, and the Social and Behavioral Sciences Commons

Research Online is the open access institutional repository for the University of Wollongong. For further information contact the UOW Library: research-pubs@uow.edu.au 


\title{
Continued participation in youth sports: the role of achievement motivation
}

\author{
Abstract \\ This study explored the antecedents of enjoyment and intention to continue in youth sports using the \\ social-cognitive model of achievement motivation with the $2 \times 2$ achievement goal modification. \\ Participants were 327 sports participants aged between 11 and 15 years. Individuals high in incremental \\ beliefs reported greater enjoyment and intention to continue. This was perhaps due to endorsing mastery- \\ approach goals. Individuals relatively high in entity beliefs reported relatively less enjoyment. This was \\ perhaps due to endorsing performance-avoidance goals. These individuals also reported relatively less \\ intention to continue regardless of their achievement goals. Findings could have implications for \\ preventing dropout from youth sports.

\section{Keywords} \\ participation, youth, continued, sports, motivation, role, achievement \\ Disciplines \\ Education | Social and Behavioral Sciences \\ Publication Details \\ Gardner, L. A., Vella, S. A. \& Magee, C. A. (2017). Continued participation in youth sports: the role of \\ achievement motivation. Journal of Applied Sport Psychology, 29 (1), 17-31.
}


Continued Participation in Youth Sports: The Role of Achievement Motivation 


\begin{abstract}
This study explored the antecedents of enjoyment and intention to continue in youth sports using the social-cognitive model of achievement motivation with the $2 \times 2$ achievement goal modification. Participants were 327 sports participants aged between 11 and 15 years. Individuals high in incremental beliefs reported greater enjoyment and intention to continue. This was perhaps due to endorsing mastery-approach goals. Individuals relatively high in entity beliefs reported relatively less enjoyment. This was perhaps due to endorsing performance-avoidance goals. These individuals also reported relatively less intention to continue regardless of their achievement goals. Findings could have implications for preventing dropout from youth sports.
\end{abstract}

Keywords: Entity beliefs; incremental beliefs; enjoyment; youth sport; dropout; socialcognitive model of achievement motivation 


\section{Continued Participation in Youth Sports: The Role of Achievement Motivation}

Approximately $50 \%$ of youth regularly participate in organized sports in the USA, Canada, and England, with rates increasing to approximately two-thirds in Australia and New Zealand (Tremblay et al., 2014). Participation rates peak between the ages of 9 and 11 years; however, there is a marked decline in participation thereafter and it is estimated that approximately $30 \%$ of adolescent participants drop out each year (Active Healthy Kids Australia, 2014; Balish, McLaren, Rainham, \& Blanchard, 2014). Relative to those who maintain participation, individuals who drop out of sport or do not participate show distinctly lower levels of health-related quality of life and mental health (Vella, Cliff, Magee, \& Okely, 2015; Vella, Cliff, \& Okely, 2014). Given that sports participation during childhood and adolescence has important physical and psychosocial health implications (Eime, Young, Harvey, Charity, \& Payne, 2013), along with a significant economic value (Australian Sports Commission, 2009), research is needed to understand factors that contribute to continued participation in youth sports.

Lack of enjoyment is the single most commonly cited reason for dropout from youth sports (Crane \& Temple, 2015). Enjoyment in this context refers to positive feelings such as fun and pleasure gained from the sports experience (Scanlan \& Simons, 1992). According to the developmental model of sport participation (Côté, Baker, \& Abernethy, 2003), enjoyment is of the greatest importance for continued participation between 7 and 15 years of age; as noted above, this age range overlaps with the ages reported to have the highest attrition rates (Boiché \& Sarrazin, 2009). This suggests that examining the antecedents of enjoyment could provide improved understanding of youth sports participation and dropout. It is also important to consider other factors such as intentions to continue in sport. Intentions have been shown to be proximal predictors of actual behaviors, including sports participation, and may therefore offer an indication of future dropout behavior (Balish et al., 2014; Prins et al., 
2010). Examining the antecedents of enjoyment and intentions may be particularly useful in preliminary dropout research as examining actual dropout behavior requires a longitudinal design. Therefore, this research could inform interventions aimed at reducing the high attrition rate which could lead to improved health outcomes for children and adolescents.

Achievement goal theory (Nicholls, 1984) is a commonly used theory in the field of sports psychology, particularly when considering sports participation and enjoyment (Duda, 2001). AGT incorporates two primary achievement goals which reflect the purpose or focus of behavior in the achievement setting (Elliot, 1997; Maehr, 1989). The two achievement goals, known as mastery and performance goals, are proposed to predict cognitive, affective, and behavioral responses in achievement settings. Mastery goals are concerned with developing ability, mastering a skill, and self-referenced judgements of competence. Performance goals are concerned with proving ability and a normative definition of competence (Nicholls, 1984). Mastery goals have been linked with greater sports enjoyment, however there is less evidence regarding the influence of performance goals (Morris \& Kavussanu, 2009). The current research aims to extend these findings and provide further insight into the processes contributing to enjoyment and participation in youth sports. This will involve utilizing the recently modified version of Dweck and Leggett's social-cognitive model of achievement motivation (SCMAM) as a theoretical framework to explore the antecedents of enjoyment in youth sports.

The SCMAM (Dweck \& Leggett, 1988) proposes that there are two implicit beliefs (incremental and entity beliefs) and two achievement goals (mastery and performance goals) which influence motivational outcomes in achievement contexts. Implicit beliefs refer to the underlying theories about one's own ability that orient individuals to pursue different goals. Incremental beliefs are characterized by a malleable and controllable conception of ability, whereas entity beliefs are encompassed by a fixed and stable conception of ability. The 
SCMAM proposes that incremental beliefs orient individuals to pursue mastery goals, and entity beliefs orient individuals to pursue performance goals. Therefore, achievement goals may be considered the more concrete aims through which individuals' implicit beliefs influence their cognitions, affect, and behavior (Cury, Elliot, Da Fonseca, \& Moller, 2006). Although individuals can hold both incremental and entity beliefs simultaneously and to different degrees, it is proposed that one set of beliefs is typically dominant (Dweck \& Leggett, 1988; Spray, Wang, Biddle, Chatzisarantis, \& Warburton, 2006). Research conducted in a number of different domains has highlighted the association between incremental beliefs and mastery goals with adaptive responses such as challenge seeking, greater motivation, increased enjoyment, and greater persistence (Biddle, Wang, Chatzisarantis, \& Spray, 2003; Dweck \& Leggett, 1988; Wang, Liu, \& Biddle, 2003). In contrast, entity beliefs and performance goals have been linked with more maladaptive responses such as avoiding challenges, decreased motivation, and lower task persistence (Biddle, Wang, Chatzisarantis, et al., 2003; Dweck \& Leggett, 1988). These negative responses have been shown to be most prominent following failure, setbacks, or under conditions of adversity (Dweck \& Leggett, 1988). This could be particularly important in the youth sports context where skills may be difficult to master and setbacks are common.

Mixed findings surrounding the role of achievement goals have recently led some to suggest that the constructs from the $2 \times 2$ achievement goal framework need to be incorporated in the SCMAM as mediating variables (Cury et al., 2006; Elliot, 1997). The 2x2 achievement goal framework is particularly relevant because it introduces a valence dimension (approach-avoidance) crossed with the original performance-mastery dimension. The approach component is focused on the positive possibility of demonstrating competence, whereas the avoidance component is focused on avoiding the negative possibility of demonstrating incompetence (Elliot \& McGregor, 2001). It is proposed that the more precise 
approach-avoidance distinction may lead to significantly different outcomes that are difficult to interpret when the dimensions are collapsed into a dichotomous framework (Cury et al., 2006; Elliot, 1997). Research suggests that individuals endorsing incremental beliefs will be tend to adopt mastery-approach and mastery-avoidance goals, whereas individuals endorsing entity beliefs will tend to adopt performance-approach and performance-avoidance goals (Cury et al., 2006). As with implicit beliefs, individuals can adopt more than one goal at once and thus research tends to focus on the degree to which goals are adopted (Elliot \& McGregor, 2001).

The $2 \times 2$ framework has received particular attention and support in the sporting domain. Notably, much of this support has been for the adaptive nature of mastery-approach goals. For example, mastery-approach goals are associated with positive outcomes in sport including enjoyment, effort, motivation, satisfaction, and performance, while being inversely associated with negative factors such as worry and amotivation (Conroy, Kaye, \& Coatsworth, 2006; Morris \& Kavussanu, 2009; Puente-Díaz, 2012; Stevenson \& Lochbaum, 2008). In contrast, performance-avoidance goals are linked with negative outcomes including reduced effort, decreased motivation, and poorer performance (Elliot, Cury, Fryer, \& Huguet, 2006). However, there have been mixed results concerning the influence of performanceapproach and mastery-avoidance goals on motivational outcomes. For example, performanceapproach goals have been associated with positive outcomes such as intrinsic motivation in some studies, whereas they have been associated with negative outcomes such as cognitive anxiety in others (Conroy et al., 2006; Stenling, Hassmén, \& Holmström, 2014; Wang, Liu, Lochbaum, \& Stevenson, 2009). Additionally, mastery-avoidance goals have been associated with negative outcomes such as worry and reduced intrinsic motivation, whereas they have produced null results in other research (Conroy et al., 2006; Puente-Díaz, 2012). Although individuals often have a dominant achievement goal, these achievement goals can be 
contextually and temporally specific (Van Yperen, 2006). Therefore, the associations between achievement goals and enjoyment/intention to continue in youth sports may be different from the aforementioned research. Of the little evidence that exists in regards to enjoyment in youth sports, performance-approach and mastery-avoidance goals have typically failed to produce positive or negative associations (Morris \& Kavussanu, 2009). Therefore, the current paper aims to further explore these relationships, as well as new relationships, by investigating the links between implicit beliefs, the four achievement goals, enjoyment, and intention to continue.

Given that the addition of the $2 \times 2$ framework to the SCMAM is relatively recent, there is a paucity of research examining the relationships proposed by this model. Research in the intelligence (Cury et al., 2006), physical activity (Stevenson \& Lochbaum, 2008), and sporting (Stenling et al., 2014) domains has demonstrated that mastery-approach and performance-avoidance goals play a key role. For example, mastery-approach goals have been found to mediate the positive associations between incremental beliefs and outcomes such as intrinsic motivation for an IQ test and autonomy for leisure time exercise, as well as the negative association with cognitive sports anxiety. Conversely, performance-avoidance goals mediated the negative relationships between entity beliefs and outcomes such as test performance and perceived leisure time exercise autonomy, as well as the positive relationship with cognitive sports anxiety. Interestingly, Stenling et al. (2014) also found performance-approach goals mediated the relationship between entity beliefs and cognitive anxiety for female athletes but not males. The present research would be the first to test these relationships in regards to enjoyment and intention to continue in youth sports.

It is important to note that much of the research utilizing implicit beliefs and the $2 \times 2$ framework incorporates perceived competence as another core factor in the model. The precise role of perceived competence in this model is unclear; it has been theorized that 
perceived competence moderates the effects of achievement goals on outcomes in some research, while it acts as an independent antecedent of achievement goals in other research (Cury et al., 2006; Dweck \& Leggett, 1988). Both perspectives have received mixed results (Cury et al., 2006; Wang et al., 2009). Given this uncertainty, we do not believe that placing perceived competence in any of these roles is justified. Therefore, consistent with previous research in youth sports (Biddle, Wang, Kavussanu, \& Spray, 2003), we have chosen to control for perceived competence in our analyses and focus on the remainder of the model and its implications for enjoyment and intention to continue in youth sports.

The aim of the current research is to explore the relationships between implicit beliefs, achievement goals, enjoyment and intention to continue in youth sports by utilizing the SCMAM with the 2x2 achievement goal modification. Given that enjoyment is a primary predictor of dropout, and that intentions often predict actual behaviors, exploring the possible antecedents and mechanisms by which enjoyment and intention to continue are influenced could provide valuable information regarding the high dropout rate in adolescent sports. Based on theory and past findings, it is hypothesized that: (a) incremental beliefs will be associated with greater levels of enjoyment and intention to continue; (b) entity beliefs will be associated with lower levels of enjoyment and less intention to continue; (c) incremental beliefs will lead to the adoption of mastery-based goals; (d) entity beliefs will lead to the adoption of performance-based goals; (e) the relationship between incremental beliefs and enjoyment/intention to continue will be mediated by mastery-approach goals; and, (f) the relationship between entity beliefs and enjoyment/intention to continue will be mediated by performance-avoidance goals.

\section{Methods}

\section{Participants}


Participants were 393 students from non-government high schools in the New South Wales region of Australia. Regular sports participants were those individuals who had participated in an organized sport at least once per week for at least three months or an entire sports season over the past year (Vella et al., 2015). Non-regular sports participants $(\mathrm{n}=58)$ and cases with missing data $(n=8)$ were excluded from the study. The remaining 327 regular sports participants (77 males, 250 females) were between 11 and 15 years of age $(M=13.03$, $S D=.84)$. Regular participation in organized team sports was reported by $82.3 \%(\mathrm{n}=269)$ and regular participation in organized individual sports was reported by $66.1 \%(n=216)$. Twenty-five different main sports were reported, with the most common being soccer ( $\mathrm{n}=$ $64,19.6 \%)$, netball $(n=52,15.9 \%)$, and dancing $(n=43,13.1 \%)$. On average, participants had been participating in their main sport for 5.41 years $(S D=3.06)$ and trained 2.74 days $(S D=1.30)$ per week. Data were inspected for outliers and most variables approximated a normal distribution except for incremental beliefs and mastery-approach goals which were negatively skewed. This is a common issue in youth sports research as sports participants have been shown to be predominantly driven by incremental beliefs and mastery-approach goals (Stenling et al., 2014; Wang et al., 2009). The analytic approach used in this paper (described below) is also robust to violations of these assumptions.

\section{Procedure}

Ethics approval for the study was gained via the institutional research ethics committee. Schools were contacted and informed about the study. Participants were provided with a questionnaire booklet to be completed during a normal Physical Education lesson.

\section{Measures}

Implicit Beliefs. Incremental and entity beliefs were assessed using the Conceptions of the Nature of Athletic Ability Questionnaire-Version 2 (CNAAQ-2; Biddle, Wang, Chatzisarantis, et al., 2003). The questionnaire consists of 12 items reflecting four subscales. 
Incremental beliefs were assessed by summing the Learning subscale (e.g., 'You need to learn and to work hard to be good at sport') and the Improvement subscale (e.g., 'In sport, if you work hard at it you will always get better'). Entity beliefs were assessed by summing the Gift subscale (e.g., 'To be good at sport you need to be naturally gifted') and the Stable subscale (e.g., 'It is difficult to change how good you are at sport'). Participants responded on a five-point scale ranging from 1 (strongly disagree) to 5 (strongly agree). This scale has been shown to produce valid and reliable estimates of incremental and entity beliefs in youth populations (Biddle, Wang, Chatzisarantis, et al., 2003). Cronbach's alpha for the four subscales ranged from $.50-.78$.

Achievement Goals. The Achievement Goals Questionnaire for Sport (AGQ-S; Conroy, Elliot, \& Hofer, 2003) was used to assess achievement goals. The questionnaire consists of 12 items assessing performance-approach goals (e.g. 'It is important for me to perform better than others'), performance-avoidance goals (e.g. 'I just want to avoid performing worse than others'), mastery-approach goals (e.g. 'I want to perform as well as it is possible for me to perform'), and mastery-avoidance goals (e.g. 'I worry that I may not perform as well as I possibly can'). Participants indicated how much they agreed or disagreed with each item with respect to their main sport. Items were rated on a seven-point scale ranging from 1 (not at all like me) to 7 (completely like me). The scale has demonstrated good reliability and validity in the youth sports context (Conroy et al., 2003). In the current study, the Cronbach's alpha coefficients for the four subscales ranged from .71- .83.

Enjoyment. Enjoyment was assessed using the Enjoyment subscale of the Sport Commitment Model (SCM; Scanlan, Simons, Carpenter, Schmidt, \& Keeler, 1993). The subscale consists of four items (e.g., 'Do you have fun playing your main sport?') rated on a five-point scale ranging from 1 (not at all) to 5 (very much). The four items were summed to compute a total score. Previous research has supported the validity and reliability of this 
measure in similar populations (Kalaja, Jaakkola, Liukkonen, \& Watt, 2010). In the present study the Cronbach's alpha coefficient was $\alpha=.97$.

Intention to continue. Intention to continue was assessed using one item developed for this study ('I intend to participate in my main sport next season'). The item was rated on a five-point scale ranging from 1 (strongly disagree) to 5 (strongly agree). Although a reliability estimate cannot be calculated in this case, single item measures have been shown to produce good reliability and predictive validity, as well as being useful to reduce respondent burden (Bergkvist, 2015; Richard \& Donnellan, 2012).

Covariates. A number of covariates were included in the analyses. Firstly, given the aforementioned uncertainty surrounding the role of perceived competence in the different versions of the social cognitive model of achievement motivation, perceived competence was controlled for to reduce the potential for residual confounding. This was done using the Athletic Competence subscale of Harter's (1985) Self-Perception Profile for Children $(\alpha=$ .78). The remaining covariates are predominately related to social support in youth sports. This is because the three key social figures (parents, coaches, and peers) have been shown to be salient predictors of sports participation and related outcomes (Crane \& Temple, 2015; McCarthy \& Jones, 2007). Additionally, there is some evidence to suggest that social agents shape implicit beliefs and therefore may potentially be confounding factors (Slater, Spray, \& Smith, 2012). ;The Perceived Parental Support Scale (Van Yperen, 1995) was used to assess perceived parental support $(\alpha=.78)$; the Sport Friendship Quality Scale (Weiss \& Smith, 1999) was used to assess perceived friendship quality in sport $(\alpha=.90)$; the Social subscale of the Self-Perception Profile for Children (Harter, 1985) was used to assess peer acceptance $(\alpha=.82)$; and, the direct version of the Coach-Athlete Relationship Questionnaire (CART-Q; Jowett \& Ntoumanis, 2004) was used to assess perceived coach-athlete relationship quality. As suggested by previous research (Lafrenière, Jowett, Vallerand, \& Carbonneau, 2011), the 
subscales of the CART-Q were combined to produce an overall measure of coach-athlete relationship quality which resulted in a Cronbach's alpha coefficient of $\alpha=.94$. Participants' age and sex were also included and controlled for in the analyses.

\section{Design/Statistical Analysis}

All analyses were conducted using Mplus version 7 (Muthén \& Muthén, 1998-2012). Correlations were first examined to assess the bivariate relationships between variables. Linear regression models were then tested to examine the total effects (i.e., the $c$ paths) linking incremental and entity beliefs with levels of enjoyment and intention to continue. These regression models controlled for age, sex, level of perceived competence, perceived parental support, perceived friendship quality, peer acceptance, and the coach-athlete relationship quality. Two multiple mediation path models were then tested to examine the direct effects ( $c^{\prime}$ paths) and indirect effects ( $a b$ paths) linking incremental and entity beliefs with enjoyment via achievement goals (separate indirect paths were examined for each of the four achievement goals). These models controlled for age, sex, level of perceived competence, perceived parental support, perceived friendship quality, peer acceptance, and the coach-athlete relationship quality. A bootstrapping procedure with 5000 resamples was used to test the indirect effects with significance determined from $95 \%$ confidence intervals. The multiple mediation path models were then tested again, with intention to continue modelled as the dependent variable. Results are reported in terms of unstandardized $(B)$ regression coefficients, with the statistical significance of the indirect paths determined on the basis of $95 \%$ confidence intervals.

\section{Results}

\section{Descriptive Statistics and Correlations}

The descriptive statistics for implicit beliefs, the $2 \times 2$ achievement goals, enjoyment, and intention to continue are presented in Table 1. Participants tended to endorse higher 
levels of incremental beliefs than entity beliefs. Participants also had high levels of masteryapproach goals, enjoyment, and intention to continue. Incremental beliefs demonstrated significant positive correlations with the two mastery goals, performance-approach goals, enjoyment, and intention to continue. Entity beliefs were positively correlated with the two performance goals and mastery-avoidance goals, whereas they were negatively correlated with mastery-approach goals, enjoyment, and intention to continue.

\section{Models Linking Implicit Beliefs with Enjoyment}

Incremental beliefs and enjoyment. The multiple mediation path model linking incremental beliefs with enjoyment through the $2 \times 2$ achievement goals is shown in Figure 1 a. Incremental beliefs were found to be positively associated with mastery-approach goals, mastery-avoidance goals, and performance-approach goals. However, only mastery-approach goals and performance-avoidance goals were significantly related to enjoyment levels. The total and direct effects linking incremental beliefs with enjoyment were not significant. Further, the indirect paths linking incremental beliefs with enjoyment indicated that masteryavoidance goals, $B=.02,95 \%$ CI [-.001, .05]; performance-approach goals, $B=.01[-.001$, $.04]$; and, performance-avoidance goals, $B=-.01$, [-.04, .01]; were not significant. However, incremental beliefs were indirectly associated with enjoyment via mastery-approach goals, $B$ $=.05,[.02, .10]$.

Entity beliefs and enjoyment. The multiple mediation path model linking entity beliefs with enjoyment through the $2 \times 2$ achievement goals is illustrated in Figure 1b. Entity beliefs were found to be positively associated with mastery-avoidance goals, performanceapproach goals, and performance-avoidance goals. However, only mastery-approach goals and performance-avoidance goals were significantly related to enjoyment levels. The total and direct effects linking entity beliefs with enjoyment were not significant. The indirect paths linking entity beliefs with enjoyment via mastery-approach goals, $B=.001[-.01, .01]$; 
mastery-avoidance goals, $B=.01[-.01, .03]$; and, performance-approach goals, $B=.02[-$ $.004, .05]$, were also not significant. However, entity beliefs were indirectly associated with enjoyment via performance-avoidance goals, $B=-.03$, [-.07, -.01].

\section{Models Linking Implicit Beliefs with Intention to Continue}

Incremental beliefs and intention to continue. The multiple mediation path model linking incremental beliefs with intention to continue through the $2 \times 2$ achievement goals is illustrated in Figure 1c. Incremental beliefs were found to be positively associated with mastery-approach goals, mastery-avoidance goals, and performance-approach goals. However, only mastery-approach goals were significantly related to intention to continue. The total and direct effects linking incremental beliefs with intention to continue were not significant. The indirect paths linking incremental beliefs with intention to continue via mastery-avoidance goals, $B=.01[-.002, .01]$; performance-approach goals, $B=.002[-.003$, $.01]$; and, performance-avoidance goals, $B=.0003$, [-.006, .001]; were also not significant. However, incremental beliefs were linked with intention to continue indirectly through mastery-approach goals, $B=.02,[.01, .04]$.

Entity beliefs and intention to continue. The multiple mediation path model linking entity beliefs with intention to continue through the $2 \times 2$ achievement goals is illustrated in Figure 1d. Entity beliefs were found to be positively associated with mastery-avoidance goals, performance-approach goals, and performance-avoidance goals. However, only mastery-approach goals were significantly related to intention to continue. The total effect of entity beliefs on intention to continue was not significant, however, the association between entity beliefs and intention to continue while accounting for the $2 \times 2$ achievement goals (direct effect) was significant. The indirect paths linking entity beliefs with intention to continue via mastery-approach goals $B=.001[-.004, .01]$; mastery-avoidance goals, $B=.003$ 
$[-.001, .01]$; performance-approach goals, $B=.003[-.01, .01]$; and, performance-avoidance goals, $B=-.001,[-.01, .01]$ were not significant.

\section{Discussion}

This study indicated that implicit beliefs about ability and achievement goals are significantly associated with enjoyment and intentions to continue in youth sports. Individuals who believe their ability can be changed and developed (i.e., endorse high levels of incremental beliefs) experienced greater enjoyment and intention to continue in their sport due to their focus on demonstrating self-referenced mastery (mastery-approach goals). Although the sample tended to endorse high levels of incremental beliefs, mastery-approach goals, and experienced high levels of enjoyment and intention to continue, individuals who were relatively high on entity beliefs (i.e., believe their ability is stable and uncontrollable) experienced relatively less enjoyment due to their focus on avoiding demonstrating normative incompetence (i.e., performance-avoidance goals). In regards to intention to continue, individuals with relatively high levels of entity beliefs reported relatively less intention to continue regardless of their achievement goals. This provides new insights into the antecedents of enjoyment and intention to continue, and may therefore have important implications for understanding dropout behavior in youth sports.

The findings that incremental beliefs were positively associated enjoyment and intention to continue, and entity beliefs were negatively associated with enjoyment and intention to continue were consistent with theoretical expectations. Similar findings in regards to incremental beliefs and enjoyment have been established in the physical activity domain (Biddle, Wang, Chatzisarantis, et al., 2003; Wang et al., 2003). However, there has been less evidence demonstrating the negative effect of entity beliefs on enjoyment and intention to continue. Although Wang et al. (2003) found that individuals high in entity beliefs enjoyed physical activity/physical education classes significantly less than individuals 
high in incremental beliefs, the majority of the sample endorsing entity beliefs consisted of non-athletes. The link between entity beliefs and enjoyment may be particularly important as there is currently limited research examining non-enjoyment in youth sports which is the most commonly reported reason for dropout (Crane \& Temple, 2015; McCarthy \& Jones, 2007). The current research is the first to examine the relationships between entity beliefs and enjoyment/intention to continue among youth sports participants, and therefore adds to the existing knowledge in the area.

Also consistent with theory, incremental beliefs led to the adoption of masteryapproach and mastery-avoidance goals, whereas entity beliefs led to the adoption of performance-approach and performance-avoidance goals. However, the results demonstrated that incremental beliefs were also associated with performance-approach goals, and entity beliefs were also associated with mastery-avoidance goals. It is feasible that athletes who endorse incremental beliefs may still aim to demonstrate competence, despite it being in comparison to others (i.e., adopt a performance-approach goal), as they may not fear failure and/or they may perceive success as a likely outcome due to their malleable ability. Alternatively, these individuals may use normative comparisons as an indication of selfimprovement or learning. It is also possible that individuals who endorse entity beliefs may aim to avoid demonstrating incompetence, despite it being self-referenced (i.e., adopt a mastery-avoidance goal), as they may perceive their fixed level of ability to be insufficient for the task. However, as demonstrated in the literature and the current findings, the most consistent and strong links have been between incremental beliefs and mastery-approach goals, and entity beliefs and performance-avoidance goals (Stenling et al., 2014; Stevenson \& Lochbaum, 2008).

The findings that incremental beliefs were associated with enjoyment and intention to continue indirectly through mastery-approach goals and that entity beliefs were associated 
with enjoyment indirectly through performance-avoidance goals are consistent with previous research examining outcomes such as motivation for an IQ task, test performance, autonomy for leisure time exercise, and cognitive anxiety in athletes (Cury et al., 2006; Stenling et al., 2014; Stevenson \& Lochbaum, 2008). However, neither mastery-avoidance goals nor performance-approach goals mediated the association between implicit beliefs and enjoyment levels or intention to continue. Given the equivocal findings surrounding these dimensions in the literature (Cury et al., 2006; Puente-Díaz, 2012; Stenling et al., 2014), no hypotheses about their role were made in the current paper. It is possible that the aversive focus of mastery-avoidance goals may undermine the increased enjoyment levels attributable to endorsing higher levels of incremental beliefs and being focused on self-referenced performance (i.e., mastery goals). This may be particularly salient in youth sports given that adolescence is a period often associated with social instability and adversity, and thus individuals may not want to risk embarrassing themselves in front of their peers (FraserThomas, Côté, \& Deakin, 2005; Stevenson \& Lochbaum, 2008). In contrast, the lack of findings surrounding performance-approach goals may be due to the positive focus of the approach component being undermined by the negative influence of normative based evaluations of competence. Similarly, this issue may be prominent in youth sports as it is a competitive context where performance is easily and often evaluated (Stenling et al., 2014).

\section{Theoretical and practical implications}

The present findings provide important insights into the factors underlying enjoyment and intentions to continue in youth sports. Using the SCMAM as a theoretical framework, we demonstrated that adaptive implicit beliefs and achievement goals facilitate enjoyment and intentions to continue. In contrast, maladaptive implicit beliefs and achievement goals inhibit enjoyment and intentions to continue. The $2 \times 2$ achievement goal framework appears to be a valuable addition to the SCMAM as the more precise dimensions demonstrated different 
associations with implicit beliefs and enjoyment/intentions to continue, and thus greater predictive power. These findings would have been lost if the approach-avoidance distinction was collapsed into the original dichotomous framework. This may at least partially explain previous mixed findings of studies utilizing AGT to explore the antecedents of enjoyment in regards to performance goals.

The novel findings concerning reduced enjoyment may be particularly important as research has tended to focus mainly on enjoyment and neglected investigating the antecedents of non-enjoyment. Although we consider the $2 \times 2$ achievement goal framework to be an improvement on the original dichotomous framework, the finding that only two of the achievement goals (mastery-approach and performance-avoidance) were significant in the mediation models may still be considered supportive of a dichotomous framework (Stevenson \& Lochbaum, 2008). However, given that mastery-avoidance and performanceapproach goals showed unexpected associations with entity beliefs and incremental beliefs respectively, the $2 \times 2$ achievement goal framework requires further investigation.

Given that lack of enjoyment is a primary factor in the decision to drop out of youth sports and that intentions are considered proximal predictors of actual behaviors, the current findings could have important practical implications. For example, as previous research has supported the notion that implicit beliefs can be adjusted (Spray et al., 2006), intervention strategies to promote enjoyment and thereby prevent dropout may focus on the promotion of incremental beliefs among youth. This could be particularly important among adolescent sports participants as not only is it the period where dropout dramatically increases, but it is also the period when individuals' conceptions of ability become more differentiated (Balish et al., 2014; Nicholls \& Miller, 1983). Prior to this, children tend to universally adopt incremental beliefs (Leondari \& Gialamas, 2002). Vella, Cliff, Okely, Weintraub, and Robinson (2014) proposed a number of strategies for coaches to promote incremental beliefs 
among athletes such as defining success as effort, promoting learning, focusing on effort and persistence, facilitating challenge, providing high expectations, and promoting the value of failure. Furthermore, given that mastery-approach goals indirectly linked incremental beliefs with enjoyment, coaches and parents should avoid promoting comparison standards and instead encourage youth to strive to improve their personal development, learn skills, and have fun. This could be demonstrated at the organizational level by implementing youth sports programs that do not record game scores or competition points, a strategy already employed in junior Australian football (AFL) and soccer/football leagues in Australia.

\section{Strengths and limitations}

A theoretical concern that arose in the current study and other similar research is that participants tended to endorse incremental beliefs and adopt mastery-approach goals to a greater extent than entity beliefs and the other achievement goals (Stenling et al., 2014; Stevenson \& Lochbaum, 2008). This issue may be especially common in the sports domain as sports participants are a population that has been shown to be predominantly driven by incremental beliefs and mastery-approach goals (Stenling et al., 2014; Wang et al., 2009). Similarly, the sample reported high levels of enjoyment and intention to continue which may produce ceiling effects. However, this was to be expected given the sample consists only of regular sports participants. Although the conclusions are discussed in relative terms, rather than absolute terms, caution must be used as individuals experiencing relatively low levels of enjoyment and intention to continue still exhibited scores greater than the midpoint of the scales. Future research may benefit from including participants that have recently dropped out of sport. Additionally, perceived competence was controlled for in the analyses, but we did not examine whether it acted as a moderator or a direct antecedent in the model. This reflects the continuing uncertainty about the role of perceived competence in youth sports 
research (Cury et al., 2006; Wang et al., 2009). Future research is needed to investigate the specific role of perceived competence in relation to implicit beliefs and achievement goals.

There are also some methodological limitations that warrant discussion. The crosssectional design of the study does not allow causation to be determined. Therefore, we cannot rule out other possible explanations and directional relationships. For example, it might be possible that high enjoyment of a sport could shape one's achievement goals. Future research using longitudinal and experimental designs is needed to explore the temporal associations between variables. Future research might also benefit from including measures of achievement goal orientations, which differ slightly from achievement goals. Achievement goal orientations reflect the general disposition to pursue mastery or performance goals, as compared to achievement goal involvement which refers to the more concrete purpose or focus of the behavior (Elliot, 1997; Maehr, 1989). Therefore, achievement goal orientations share similar characteristics with implicit beliefs. Also like implicit beliefs, achievement goal orientations tend to be more stable than achievement goals (Conroy \& Hyde, 2014). Therefore, results may vary from those explored in the current research and other relationships, such as those between implicit beliefs and achievement goal orientations may become evident. Another limitation is use of self-report questionnaires which may be subject to socially desirable responses (Podsakoff, MacKenzie, Lee, \& Podsakoff, 2003). Although the reliability and validity of single-item measures has been supported in previous research, the use of only one item to measure intention to continue could be a potential limitation, and multi-item scales should be considered in future research. Future research should also include measures of both sport-specific and sport-general dropout. Finally, all participants were recruited from private high schools and thus were of a medium to high socioeconomic position. Given that socio-ecological factors such as household income and parental education have been shown to predict dropout (Vella, Cliff, \& Okely, 2014), future studies 
should also include participants from lower socio-economic positions. However, the inclusion of measures of parental, peer, and coach relationship as covariates in the analyses was a novel approach that significantly strengthened the current research.

\section{Conclusion}

This paper has provided support for the use of the SCMAM and the $2 \times 2$ achievement goal modification to understand enjoyment and intention to continue in youth sports. The findings imply that adaptive implicit beliefs and achievement goals may facilitate enjoyment and intention to continue, whereas maladaptive implicit beliefs and achievement goals may inhibit enjoyment and intention to continue. Specifically, individuals who believe that ability is malleable and increasable through effort (i.e., individuals high in incremental beliefs) experience greater levels of enjoyment and express more intention to continue, perhaps due to their focus on demonstrating self-referenced mastery (i.e., mastery-approach goals). In contrast, although less prominent, individuals endorsing relatively higher levels of entity beliefs (i.e., individuals who believe that ability is fixed) experience relatively less enjoyment and intention to continue, perhaps because of their focus on avoiding normative displays of incompetence (i.e., performance-avoidance goals). These findings provide new insights into the antecedents of enjoyment and intention to continue in youth sports. Given that lack of enjoyment has been identified as the most common reason for dropout (Crane \& Temple, 2015) and that intentions have been shown to be proximal predictors of sports participation (Balish et al., 2014; Prins et al., 2010), these findings could have important implications for promoting retention in youth sports. Sports organizations, coaches, and parents should avoid promoting comparison standards among youth athletes and instead work to establish environments that foster incremental beliefs, mastery-approach goals, and enjoyment. 


\section{References}

Active Healthy Kids Australia. (2014). Is sport enough? 2014 report card on physical activity for children and young people. Australia: Retrieved from http://www.activehealthykidsaustralia.com.au/report-cards/.

Australian Sports Commission. (2009). The economic contribution of sport to Australia. Melbourne, Australia: Retrieved from https://secure.ausport.gov.au/clearinghouse/knowledge_base/organised_sport/value_o f_sport/economic_contribution_of_sport.

Balish, S. M., McLaren, C., Rainham, D., \& Blanchard, C. (2014). Correlates of youth sport attrition: A review and future directions. Psychology of Sport and Exercise, 15, 429439. doi:10.1016/j.psychsport.2014.04.003

Bergkvist, L. (2015). Appropriate use of single-item measures is here to stay. Marketing Letters, 26, 245-255. doi:10.1007/s11002-014-9325-y

Biddle, S. J. H., Wang, C. K. J., Chatzisarantis, N. L. D., \& Spray, C. M. (2003). Motivation for physical activity in young people: Entity and incremental beliefs about athletic ability. Journal of Sports Sciences, 21, 973-989.

Biddle, S. J. H., Wang, C. K. J., Kavussanu, M., \& Spray, C. M. (2003). Correlates of achievement goal orientations in physical activity: A systematic review of research. European Journal of Sport Science, 3, 1-20. doi:10.1080/17461390300073504

Boiché, J. C. S., \& Sarrazin, P. G. (2009). Proximal and distal factors associated with dropout versus maintained participation in organized sport. Journal of Sports Science \& Medicine, 8, 9-16.

Conroy, D. E., Elliot, A. J., \& Hofer, S. M. (2003). A 2 X 2 achievement goals questionnaire for sport: Evidence for factorial invariance, temporal stability, and external validity. Journal of Sport \& Exercise Psychology, 25, 456-476. 
Conroy, D. E., \& Hyde, A. L. (2014). Achievement goal theory. In R. C. Eklund \& G. Tenenbaum (Eds.), Encyclopedia of sport and exercise psychology (Vol. 1, pp. 2-7). Thousand Oaks, CA: SAGE Publications, Inc.

Conroy, D. E., Kaye, M. P., \& Coatsworth, J. D. (2006). Coaching climates and the destructive effects of mastery-avoidance achievement goals on situational motivation. Journal of Sport and Exercise Psychology, 28, 69-92.

Côté, J., Baker, J., \& Abernethy, B. (2003). From play to practice: A developmental framework for acquisition of expertise in team sports. In J. Starkes \& K. A. Ericsson (Eds.), Expert performance in sports: Advances in research on sport expertise (pp. 89-110). Champaign, IL: Human Kinetics.

Crane, J., \& Temple, V. (2015). A systematic review of dropout from organized sport among children and youth. European Physical Education Review, 21, 114-131.

Cury, F., Elliot, A. J., Da Fonseca, D., \& Moller, A. C. (2006). The social-cognitive model of achievement motivation and the 2 × 2 achievement goal framework. Journal of Personality and Social Psychology, 90, 666-679. doi:10.1037/0022-3514.90.4.666

Duda, J. L. (2001). Achievement goal research in sport: Pushing the boundaries and clarifying some misunderstandings. In G. C. Roberts (Ed.), Advances in motivation in sport and exercise. Champaign, IL: Human Kinetics.

Dweck, C. S., \& Leggett, E. L. (1988). A social-cognitive approach to motivation and personality. Psychological Review, 95, 256-273. doi:10.1037/0033-295X.95.2.256

Eime, R. M., Young, J. A., Harvey, J. T., Charity, M. J., \& Payne, W. R. (2013). A systematic review of the psychological and social benefits of participation in sport for children and adolescents: Informing development of a conceptual model of health through sport. The International Journal of Behavioral Nutrition and Physical Activity, 10, 1-21. doi:10.1186/1479-5868-10-98 
Elliot, A. J. (1997). Integrating the "classic" and "contemporary" approaches to achievement motivation: A hierarchical model of approach and avoidance achievement motivation. In M. Maehr \& P. Pintrich (Eds.), Advances in motivation and achievement (Vol. 10, pp. 143-179). Greenwich, CT: JAI Press.

Elliot, A. J., Cury, F., Fryer, J. W., \& Huguet, P. (2006). Achievement goals, selfhandicapping, and performance attainment: A mediational analysis. Journal of Sport and Exercise Psychology, 28, 344-361.

Elliot, A. J., \& McGregor, H. A. (2001). A 2 x 2 achievement goal framework. Journal of Personality and Social Psychology, 80, 501-519.

Fraser-Thomas, J., Côté, J., \& Deakin, J. (2005). Youth sport programs: An avenue to foster positive youth development. Physical Education and Sport Pedagogy, 10, 19-40.

Harter, S. (1985). Manual for the self-perception profile for children. Denver: University of Denver.

Jowett, S., \& Ntoumanis, N. (2004). The coach-athlete relationship questionnaire (CART-Q): Development and initial validation. Scandinavian Journal of Medicine \& Science in Sports, 14, 245-257. doi:10.1046/j.1600-0838.2003.00338.x

Kalaja, S., Jaakkola, T., Liukkonen, J., \& Watt, A. (2010). The role of gender, enjoyment, perceived competence, and fundamental movement skills as correlates of the physical activity engagement of finnish physical education students. Scandinavian Sport Studies Forum, 1, 69-87.

Lafrenière, M.-A. K., Jowett, S., Vallerand, R. J., \& Carbonneau, N. (2011). Passion for coaching and the quality of the coach-athlete relationship: The mediating role of coaching behaviors. Psychology of Sport \& Exercise, 12, 144-152. 
Leondari, A., \& Gialamas, V. (2002). Implicit theories, goal orientations, and perceived competence: Impact on students' achievement behavior. Psychology in the Schools, 39, 279-291. doi:10.1002/pits.10035

Maehr, M. (1989). Thoughts about motivation. In C. Ames \& R. Ames (Eds.), Research on motivation in education: Goals and cognitions (Vol. 3, pp. 299-315). Orlando, FL: Academic Press.

McCarthy, P. J., \& Jones, M. V. (2007). A qualitative study of sport enjoyment in the sampling years. Sport Psychologist, 21, 400-416.

Morris, R. L., \& Kavussanu, M. (2009). The role of approach-avoidance versus task and ego goals in enjoyment and cognitive anxiety in youth sport. International Journal of Sport and Exercise Psychology, 7, 185-202. doi:10.1080/1612197X.2009.9671899

Muthén, L. K., \& Muthén, B. O. (1998-2012). Mplus Users Guide. Seventh Edition. Los Angeles, CA: Muthén \& Muthén.

Nicholls, J. G. (1984). Achievement motivation: Conceptions of ability, subjective experience, task choice, and performance. Psychological Review, 91, 328-346.

Nicholls, J. G., \& Miller, A. T. (1983). The differentiation of the concepts of difficulty and ability. Child Development, 54, 951-959.

Podsakoff, P. M., MacKenzie, S. B., Lee, J.-Y., \& Podsakoff, N. P. (2003). Common method biases in behavioral research: A critical review of the literature and recommended remedies. The Journal of Applied Psychology, 88, 879-903.

Prins, R. G., van Empelen, P., te Velde, S. J., Timperio, A., van Lenthe, F. J., Tak, N. I., . . Oenema, A. (2010). Availability of sports facilities as moderator of the intentionsports participation relationship among adolescents. Health Education Research, 25, 489-497. 
Puente-Díaz, R. (2012). The effect of achievement goals on enjoyment, effort, satisfaction and performance. International Journal of Psychology, 47, 102-110.

Richard, L., \& Donnellan, B. M. (2012). Estimating the reliability of single-item life satisfaction measures: Results from four national panel studies. Social Indicators Research, 105, 323-331. doi:10.1007/s11205-011-9783-z

Scanlan, T. K., \& Simons, J. P. (1992). The construct of sport enjoyment. In G. C. Roberts (Ed.), Motivation and exercise (Vol. 11, pp. 65-83). Champaign IL: Human Kinetics. Scanlan, T. K., Simons, J. P., Carpenter, P. J., Schmidt, G. W., \& Keeler, B. (1993). The Sport Commitment Model: Measurement development for the youth-sport domain. Journal of Sport \& Exercise Psychology, 15, 16-38.

Slater, M. J., Spray, C. M., \& Smith, B. M. (2012). "You're only as good as your weakest link": Implicit theories of golf ability. Psychology of Sport \& Exercise, 13, 280-290.

Spray, C. M., Wang, C. K. J., Biddle, S. J. H., Chatzisarantis, N. L. D., \& Warburton, V. E. (2006). An experimental test of self-theories of ability in youth sport. Psychology of Sport \& Exercise, 7, 255-267. doi:10.1016/j.psychsport.2005.05.001

Stenling, A., Hassmén, P., \& Holmström, S. (2014). Implicit beliefs of ability, approachavoidance goals and cognitive anxiety among team sport athletes. European Journal of Sport Science, 14, 720-729. doi:10.1080/17461391.2014.901419

Stevenson, S. J., \& Lochbaum, M. R. (2008). Understanding exercise motivation: Examining the revised social-cognitive model of achievement motivation. Journal of Sport Behavior, 31, 389-412.

Tremblay, M. S., Gray, C. E., Akinroye, K. K., Harrington, D. M., Katzmarzyk, P. T., Lambert, E. V., . . Tomkinson, G. R. (2014). Physical activity of children: A global matrix of grades comparing 15 countries. Journal of Physical Activity and Health, 11, S113-S125. doi:http://dx.doi.org/10.1123/jpah.2014-0177 
Van Yperen, N. W. (1995). Interpersonal stress, performance-level, and parental support: A longitudinal-study among highly skilled young soccer players. Sport Psychologist, 9, 225-241.

Van Yperen, N. W. (2006). A novel approach to assessing achievement goals in the context of the $2 \times 2$ framework: Identifying distinct profiles of individuals with different dominant achievement goals. Personality and Social Psychology Bulletin, 32, 14321445. doi:10.1177/0146167206292093

Vella, S. A., Cliff, D. P., Magee, C. A., \& Okely, A. D. (2015). Associations between sports participation and psychological difficulties during childhood: A two-year follow up. Journal of Science and Medicine in Sport. doi:10.1016/j.jsams.2014.05.006

Vella, S. A., Cliff, D. P., \& Okely, A. D. (2014). Socio-ecological predictors of participation and dropout in organised sports during childhood. International Journal of Behavioral Nutrition and Physical Activity, 11, 62-71. doi:10.1186/1479-5868-11-62

Vella, S. A., Cliff, D. P., Okely, A. D., Weintraub, D. L., \& Robinson, T. N. (2014). Instructional strategies to promote incremental beliefs in youth sport. Quest, 66, 357370. doi:10.1080/00336297.2014.950757

Wang, C. K. J., Liu, W. C., \& Biddle, S. J. H. (2003). Female secondary students' sport ability beliefs and regulatory styles: Relationships with enjoyment, effort and boredom. Journal of Tianjin Institute of Physical Education 18, 13-18.

Wang, C. K. J., Liu, W. C., Lochbaum, M. R., \& Stevenson, S. J. (2009). Sport ability beliefs, 2 x 2 achievement goals, and intrinsic motivation: The moderating role of perceived competence in sport and exercise. Research Quarterly for Exercise and Sport, 80, 303-312.

Weiss, M. R., \& Smith, A. L. (1999). Quality of youth sport friendships: Measurement development and validation. Journal of Sport \& Exercise Psychology, 21, 145-166. 
Table 1

\section{Correlations}

\begin{tabular}{|c|c|c|c|c|c|c|c|c|}
\hline & $M$ & $S D$ & 1 & 2 & 3 & 4 & 5 & 6 \\
\hline $\begin{array}{l}\text { 1. Incremental } \\
\text { Beliefs }\end{array}$ & 25.43 & 2.87 & - & & & & & \\
\hline $\begin{array}{l}\text { 2. Entity } \\
\text { Beliefs }\end{array}$ & 13.58 & 3.87 & $-.19 * *$ & - & & & & \\
\hline $\begin{array}{l}\text { 3. Mastery- } \\
\text { Approach }\end{array}$ & 13.03 & 1.75 & $.45^{* *}$ & $-.15 * *$ & - & & & \\
\hline $\begin{array}{l}\text { 4. Mastery- } \\
\text { Avoidance }\end{array}$ & 10.59 & 2.60 & $.16^{* *}$ & $.16^{* *}$ & $.31 * *$ & - & & \\
\hline $\begin{array}{l}\text { 5. Performance- } \\
\text { Approach }\end{array}$ & 9.17 & 2.84 & $.15^{* *}$ & $.23 * *$ & $.26 * *$ & $.32 * *$ & - & \\
\hline $\begin{array}{l}\text { 6. Performance- } \\
\text { Avoidance }\end{array}$ & 9.18 & 2.79 & .01 & $.31 * *$ & .07 & $.37 * *$ & $.59 * *$ & - \\
\hline 7. Enjoyment & 18.59 & 2.66 & $.22 * *$ & $-.24 * *$ & $.40 * *$ & .07 & .05 & $-.14^{*}$ \\
\hline
\end{tabular}

Note. ${ }^{*} p<.05,{ }^{*} p<<.01$ 
$1 \mathrm{a}$.

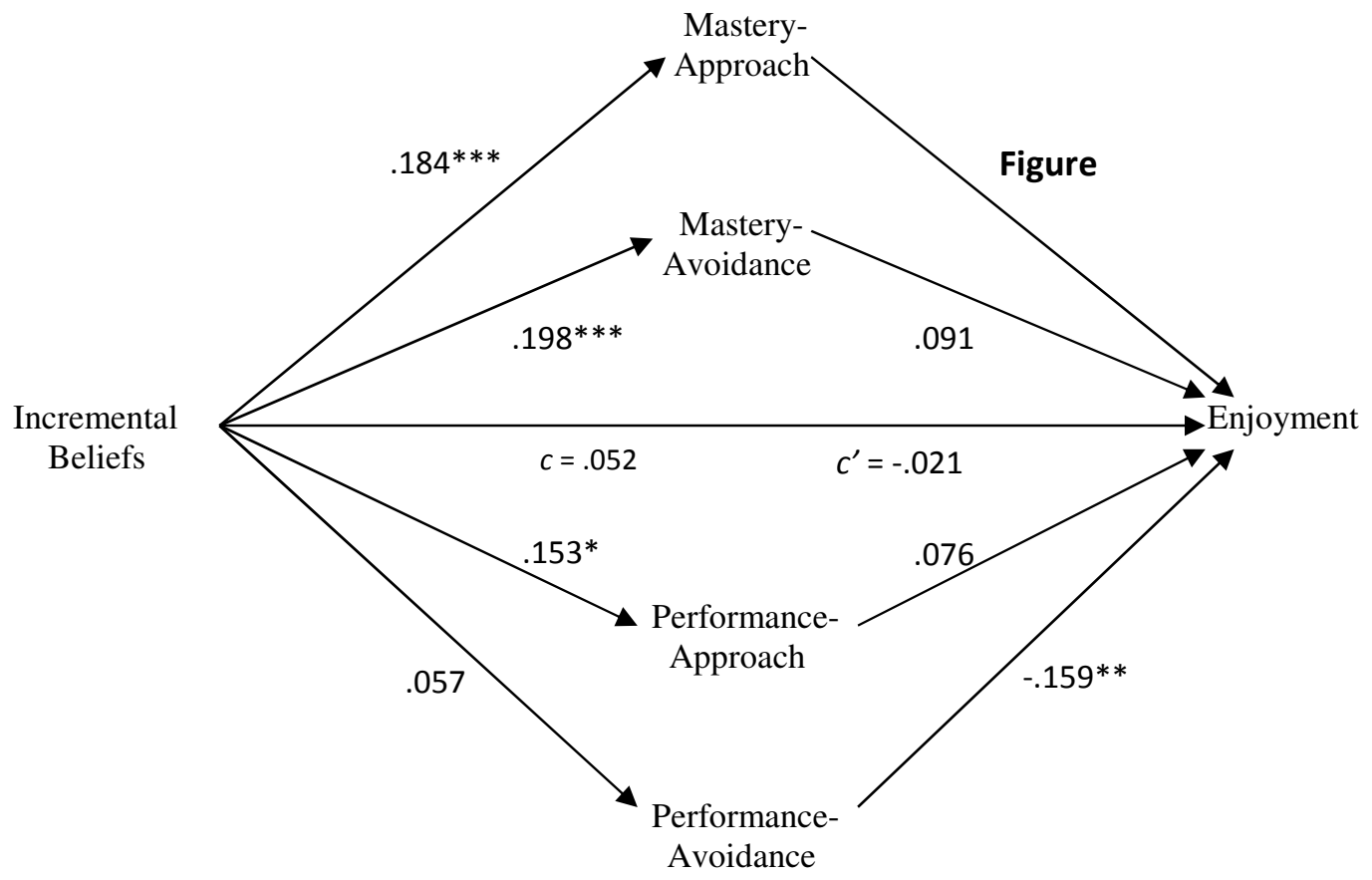

$1 b$.




$1 c$.

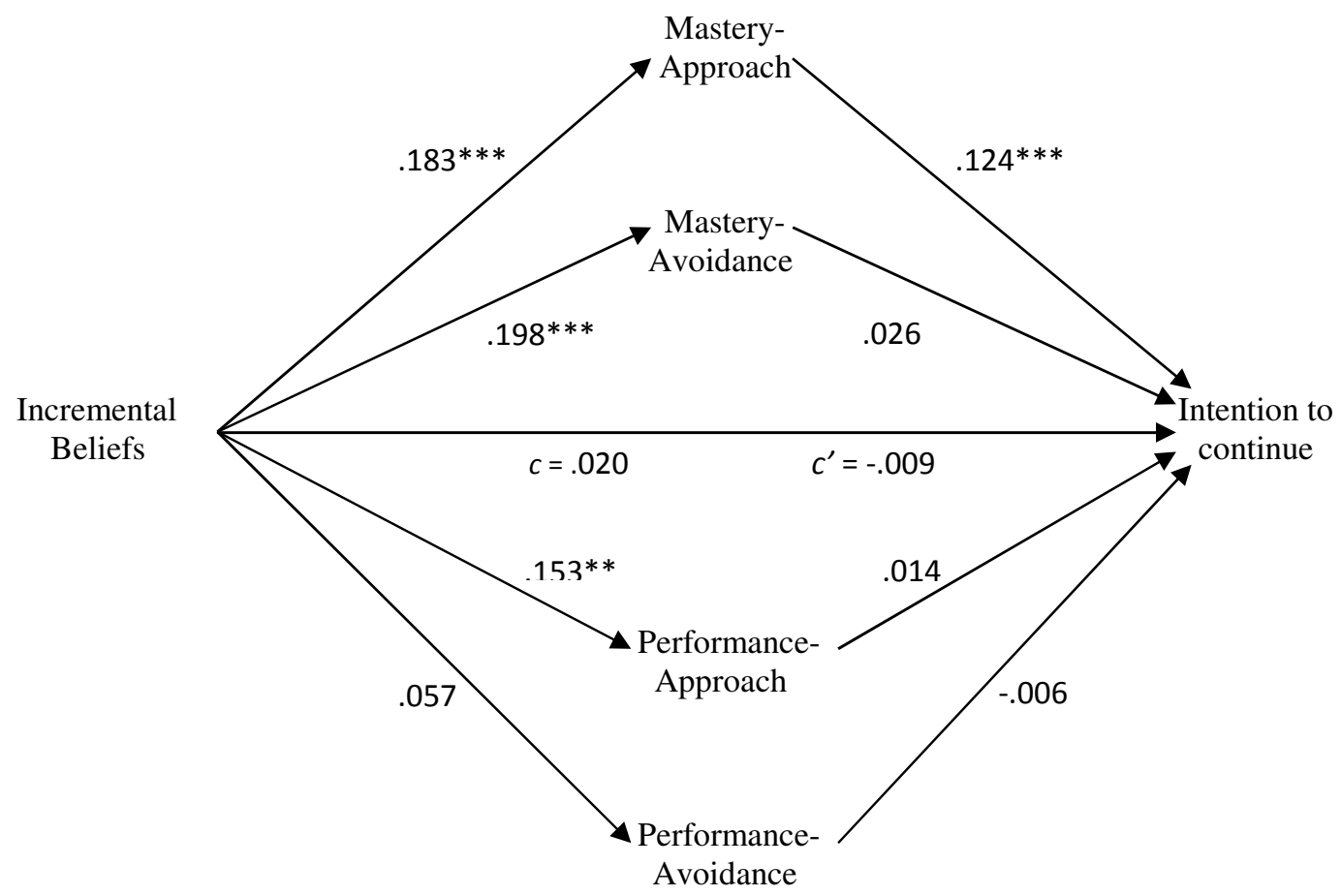

$1 d$.

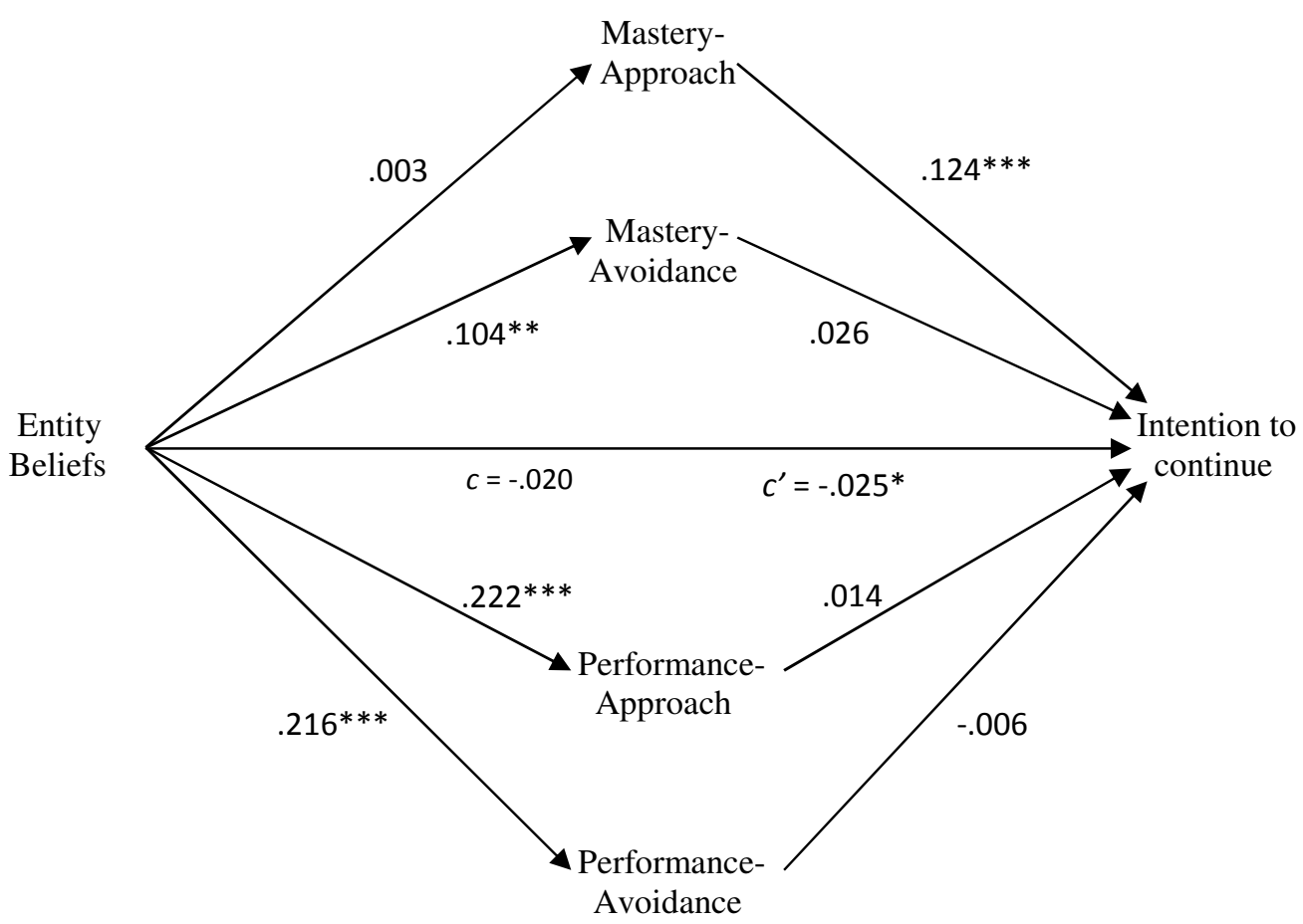




\section{Figure Captions}

Figure 1a. Multiple mediation model showing the relationship between incremental beliefs and enjoyment through the $2 \times 2$ achievement goal orientations. Unstandardised $\mathrm{B}$ are presented for each path. ${ }^{*} p<.05 . * * p<.01 . * * * p<.001$.

Figure $1 \mathrm{~b}$. Multiple mediation model showing the relationship between entity beliefs and enjoyment through the $2 \times 2$ achievement goal orientations. Unstandardised B are presented for each path. ${ }^{*} p<.05 . * * p<.01 . * * * p<.001$.

Figure 1c. Multiple mediation model showing the relationship between incremental beliefs and intention to continue through the $2 \times 2$ achievement goal orientations. Unstandardised B are presented for each path. ${ }^{*} p<.05 .{ }^{* *} p<.01 . * * * p<.001$.

Figure 1d. Multiple mediation model showing the relationship between entity beliefs and intention to continue through the $2 \times 2$ achievement goal orientations. Unstandardised B are presented for each path. $* p<.05 . * * p<.01 . * * * p<.001$. 